\title{
Complex Limb Salvage with Placental-Based Allografts: A Pilot Study
}

\author{
Danielle A. Thornburg1, Areta Kowal-Vern'2,3, William H. Tettelbach ${ }^{4,5}$, Kevin N. Foster ${ }^{3,6}$, \\ Marc R. Matthews ${ }^{3,6^{*}}$
}

\author{
${ }^{1}$ Mayo Clinic Arizona, Department of Plastic and Reconstructive Surgery, Phoenix, AZ, USA \\ ${ }^{2}$ Department of Research, Valleywise Health Medical Center, Phoenix, AZ, USA \\ ${ }^{3}$ The Arizona Burn Center, Phoenix AZ, USA \\ ${ }^{4}$ Western Peak Specialty Hospital, Bountiful, UT, USA \\ ${ }^{5}$ MiMedx Group Inc., Marietta, Georgia, USA \\ ${ }^{6}$ Department of Surgery, Valleywise Health Medical Center, Phoenix, AZ, USA \\ Email: Thornburg.Danielle@Mayo.edu, akvern@hotmail.com, btettelbach@mimedx.com, Kevin_Foster@dmgaz.org, \\ *marc_matthews@dmgaz.org
}

How to cite this paper: Thornburg, D.A., Kowal-Vern, A., Tettelbach, W.H., Foster, K.N. and Matthews, M.R. (2021) Complex Limb Salvage with Placental-Based Allografts: A Pilot Study. Surgical Science, 12, 76-94.

https://doi.org/10.4236/ss.2021.123010

Received: February 12, 2021

Accepted: March 19, 2021

Published: March 22, 2021

Copyright $\odot 2021$ by author(s) and Scientific Research Publishing Inc. This work is licensed under the Creative Commons Attribution International License (CC BY 4.0).

http://creativecommons.org/licenses/by/4.0/

\begin{abstract}
Background: Commercially available human placental amnion/chorion tissue allografts have been successfully used as protective treatment barriers for wounds and diabetic ulcers. Burn and traumatic limb injuries with exposed bone or tendon generally require surgical flaps or amputations for healing. The purpose of this study was to determine if dehydrated human amnion/ chorion membrane allografts ( $\mathrm{dHACM})$ with decellularized human collagen matrix (dHCM) could be used to salvage injured human extremities. Methods and Materials: $\mathrm{dHACM} / \mathrm{dHCM}$ was topically applied to the wounds after debridement. Negative Pressure Wound Therapy (NPWT) was concurrently initiated, primarily to bolster the tissue with moisture and contamination control. Approximately every seven days, wounds were re-evaluated for granulation tissue growth response. As needed, patients received dHACM/ dHCM and NPWT in the outpatient or home care settings after discharge. Results: Fifteen males and two females (26 extremities) were treated for fourteen burn and three Necrotizing Soft Tissue Infections (NSTI) injuries. Closure was observed in patients after two to five dHACM/dHCM applications. The dHACM/dHCM treatment was initiated: (median) 17-days after injury; NPWT for 17-days; autograft or primary closure after 21-days; discharge 25-days after the first application. Conclusion: Treatment with human placental-derived allografts provided a protective covering that enabled the healing cascade to generate granulation tissue formation in extremity wounds with exposed tendon and/or bone. In select limb salvage cases, $\mathrm{dHACM} / \mathrm{dHCM}$ treatment may be a promising alternative to amputations,
\end{abstract}


tissue rearrangements, free tissue flaps or other techniques for resolution of extremity wounds with bone and tendon exposure.

\section{Keywords}

Burns, Trauma, Placental Tissue, Amnion, Chorion, Burns, Necrotizing Soft Tissue Infections (NSTI)

\section{Introduction}

The most common interventions to heal burn and traumatic limb injuries with exposed bones and tendons include skin graft coverage, local or microvascular flaps, as well as amputations [1] [2]. Antecedent to limb removal, surgeons follow the reconstructive ladder for management of complex wounds with the following strategies: closure by primary or secondary intention, delayed primary closure, skin grafts, tissue expansion, local tissue rearrangement, and autologous tissue transfer-flaps [3] [4].

Placental amniotic membrane has been used as a wound dressing for more than 100 years [5] [6]. Currently, an additional modality has been added to the armamentarium of limb wound closure to prevent amputations. Technology has revolutionized the development of biological wound dressings for clinical use [7] [8] [9] [10] [11]. Dehydrated human amnion/chorion membrane allograft (dHACM), (MiMedx Group Inc., Marietta, GA) has been used to aid in wound closure, diabetic foot ulcers, partial and full thickness burns, donor sites, and surgically debrided areas [12]-[17]. Placental-derived allograft barriers or dressings, such as dHACM and decellularized human collagen matrix (dHCM), (MiMedx Group, Inc., Marietta, GA), also provide a protective environment which can support granulation tissue formation as well as supply a connective tissue matrix, respectively.

In utero, native human amnion/chorion membranes contain an array of factors, which play critical roles in regulating tissue development and growth. Epidermal Growth Factor (EGF), basic fibroblast growth factor (bFGF), Keratinocyte Growth Factor (KGF), Transforming Growth Factor alpha and beta (TGF- $\alpha$ and TGF- $\beta$ ), Vascular Endothelial Growth Factor (VEGF) and Tissue Inhibitors of Metalloproteinases (TIMPs) are some of the regulatory proteins that have essential roles in physiological processes required for healthy tissue generation, such as cell migration, proliferation and recruitment [10] [18] [19]. The purpose of this study was to determine if dHACM applied in tandem with dHCM ( $\mathrm{dHACM} / \mathrm{dHCM}$ ) could be used to aid in the salvage of extremities at high risk for amputation due to burns, trauma or Necrotizing Soft Tissue Infections (NSTI).

\section{Methods and Materials}

\subsection{Sample Population}

This observational retrospective pilot study performed from January 2019 through 
October 2020 was approved by the Institutional Review Board for human studies. The inclusion criteria for treatment with dHACM/dHCM were: 1) exposed bone or tendon; 2) burn, trauma, or NSTI injuries; 3) failed split thickness skin graft (STSG) applications; 4) inadequate production of granulation tissue. The exclusion criteria were: 1) deep circumferential bone burn; 2) open joint; 3) continued tissue necrosis with tangential excisional debridement (TED) in the week after admission; 4) non-clearance of tissue infection with TED or antibiotics; 5) unstable lower limb ankle joint; 6) unrepairable peripheral vascular disease (no pulse or adequate arterial run-off to the feet).

\section{2. dHACM and dHCM}

The PURION ${ }^{\circledR}$ processed dHACM and $\mathrm{dHCM}$ are cleansed and dehydrated from donor-screened and tested elective caesarean section delivered placentas [7] [8] [9] [10] [11]. These placental-derived allografts undergo terminal sterilization to further reduce the possibility of an occurrence of a non-sterile unit. dHACM contains non-viable cells; $\mathrm{dHCM}$ is derived from the placental disc and contains mostly Type 1 human collagen. Both dHACM and dHCM contain over 250 identified regulatory proteins [7] [11]. In addition, $\mathrm{AHACM}$ and $\mathrm{AHCM}$ can be stored at room temperature for five years.

\subsection{Treatment Process}

Prior to placental-derived tissue application, burn or NSTI wounds were debrided of dead or necrotic tissue with the water knife Versajet II Hydrosurgical System (Smith + Nephew, Andover, MA) [20]. They were cleansed with normal saline and a stabilized hypochlorous acid solution. Bone trephination exposed bone capillaries and arterioles to promote granulation tissue generation over the wounds and avascular areas [1] [21] [22]. Negative pressure wound therapy (NPWT) via the ACTIV.A.C ${ }^{\mathrm{TM}}$. Therapy system (3M Corporation, San Antonio, TX) was applied at $125 \mathrm{mmHg}$ to promote cleansing, limit bacteria, stimulate granulation tissue growth, and increase wound bed vascularity [23].

Once the injured area was prepared, $\mathrm{dHACM} / \mathrm{dHCM}$ were topically applied or packed (depending on wound depth), covered with either a nonadherent dressing, $3 \%$ bismuth tribromophenate petrolatum dressing, or a glycerol-hydroxyethylcellulose lubricant, and bolstered with NPWT at 50 - $100 \mathrm{mmHg}$ (Figures 1-5). The wounds were re-evaluated every seven days for granulation tissue formation after removal of the NPWT device and underlying dressing. The wound bed was appropriately debrided and $\mathrm{dHACM} / \mathrm{dHCM}$ were reapplied over or into the wound, if required. $\mathrm{dHACM} / \mathrm{dHCM}$ treatment was continued until bone, tendon and muscle were covered with adequate granulation tissue to sustain a Split Thickness Skin Graft (STSG). Skin grafts were bolstered under a NPWT device to minimize shear effect and sub-graft fluid accumulation, which could potentially damage or lift the graft off the wound bed and disrupt the intracellular signals critical for successful graft incorporation [24] [25] [26]. This practice 


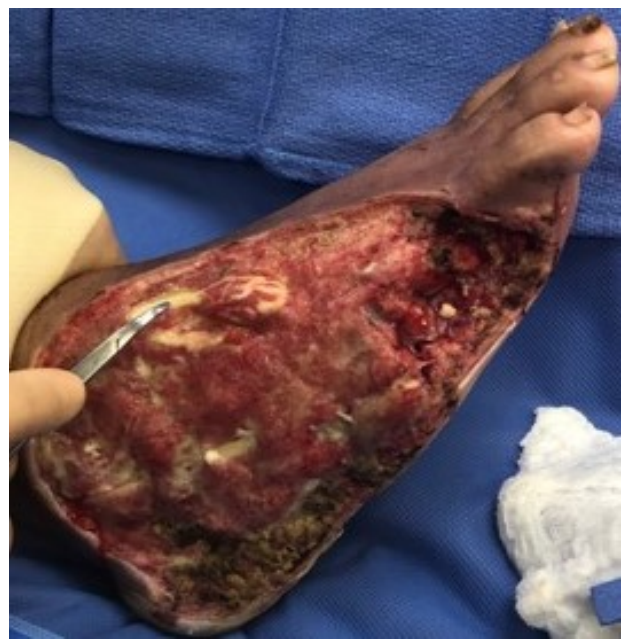

Figure 1. Transfer with contact burn wound (25-day-old wound with little toe amputation).

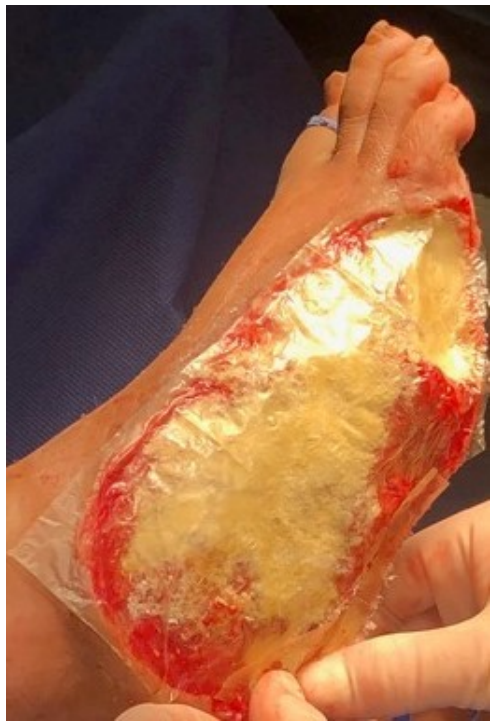

Figure 2. Additional application of $\mathrm{dHACM} / \mathrm{dHCM}$ over granulation tissue formation on the wound.

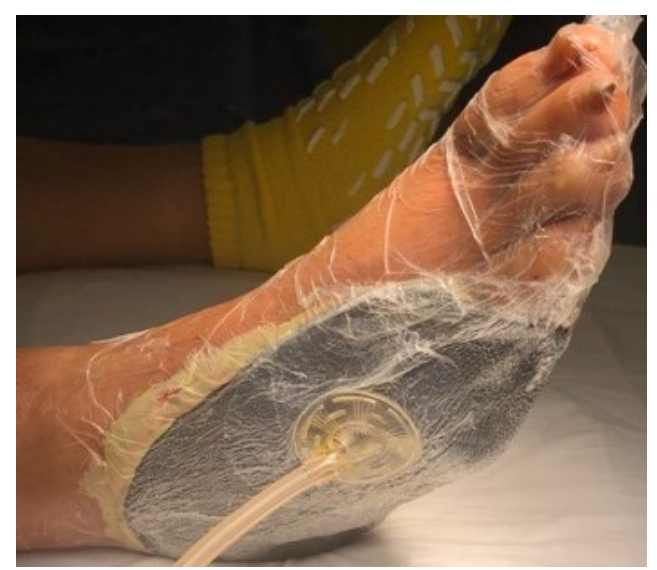

Figure 3. NPWT application over the healing wound. 


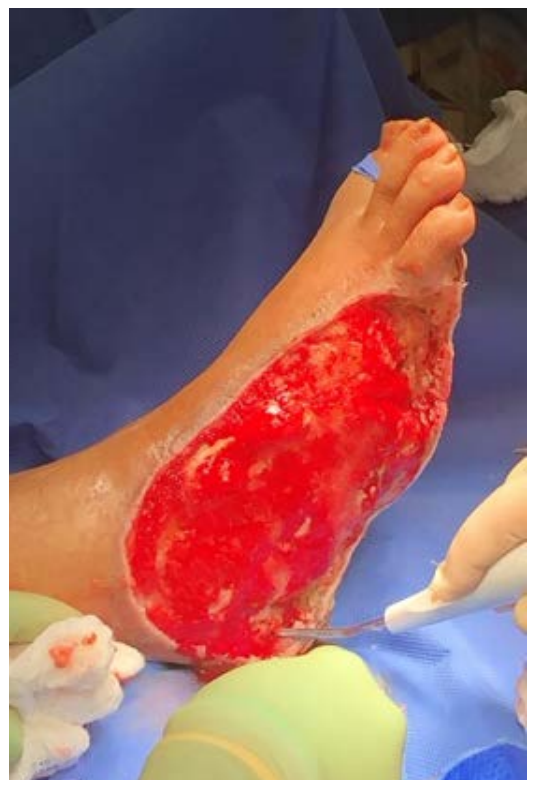

Figure 4. Healthier granulation tissue bed now evident once all dressing removed prior to split thickness skin grafting.

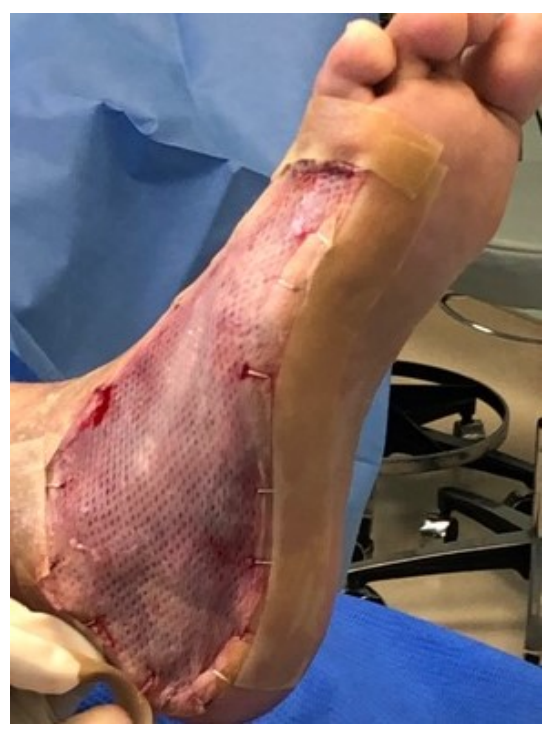

Figure 5. Split thickness skin graft application over wound granulation tissue.

was adopted in limb salvage protocols to fortify allografts such as DHACM and dHCM. To minimize disturbances to the protected wound healing environment, NPWT dressings were changed once a week instead of the usual wound care strategy of two-three times a week.

\subsection{Statistical Analysis}

Statistical analysis was performed with Statistica ${ }^{\circledR}$ (StatSoft, Tulsa, OK): descriptive statistics, one way-ANOVA, with unequal N Tukey post-hoc comparisons, and Maximum Likelihood chi-squared tests. Comparisons were made between the patients with leg, foot, combined leg and foot, and upper extremity injuries. 
One-way ANOVA and Tukey statistics compared the following: age, percent total body surface (\%TBSA), body mass index (BMI), operating room (OR) visits, extent of tangential debridement, autograft areas, length of stay (LOS), time to application of the $\mathrm{dHACM} / \mathrm{dHCM}$, time from application to autograft, time from first application to discharge, duration of NPWT use during treatment with these dressings, number of surgeries, and OR visits. Maximum Likelihood chi-squared compared ethnicity, gender, injury location, mechanism of injury, discharge location, comorbidities (diabetes, hypertension, cardiac, renal, etc.), alcohol/drug use, and infection. In all cases, a $p<0.05$ value was considered significant.

\section{Results}

Table 1 depicts the demographic characteristics of patients with tendon and bone exposure after burn injury (14 patients, 82\%) and necrotizing fasciitis (3 patients, 18\%). There were seventeen patients with 26 extremities: 11 legs, 13 feet, two upper extremities. The mean \pm standard deviation (median) age was $48.8 \pm 16.5$ (48) years; \% TBSA, $3.3 \pm 4.0$ (1.3); and length of hospital stay $43.4 \pm$ 20.7 (39) days. Ethnicity consisted of the following: seven (41\%) each for White and Hispanic/Latino patients, two (12\%) Black, and one (5.9\%) Native American Indian. The major co-morbidities were diabetes, hypertension and cardiovascular disease. Admission laboratory values showed the following median, interquartile range (IQR): C-reactive protein, 92 (39 - 225) mg/dl; glucose, 167 (114 218) mg/dl; pre-albumin, 11.0 (8 - 18) mg/dl; transferrin, 166 (129 - 214) mg/dl; and hemoglobin A1c, 7.4 (6.9 - 10.2)\%. Patients with both leg and foot involvement had a higher \%TBSA, $(p=0.02)$ and a longer LOS than those with only foot involvement, $(p=0.035)$. In addition to burns on other anatomical locations, two patients had upper extremity wounds, which received dHACM/dHCM, and closure occurred.

Table 2 shows the dHACM/dHCM treatment process duration. Wound bed preparation lasted a median of 25-days from injury or admission. The median time interval from the start of $\mathrm{dHACM} / \mathrm{dHCM}$ application to autograft placement was 25-days, and from the first application to discharge 26-days. The combined United States dollar ( $\$$ USD) cost for only the dHACM/dHCM products was (median, IQR) of $\$ 15,410(\$ 10,940-\$ 21,440)$, as shown in Table 3.

Table 1. Demographic characteristics of patients receiving dHACM and dHCM.

\begin{tabular}{cccc}
\hline & Leg & Foot & Leg-Foot \\
\hline Patients & $6(35)$ & $8(47)$ & $2(12)$ \\
Extremities & $9(35)$ & $11(42)$ & $2 \& 2(23)$ \\
Age (years) & $57.3 \pm 20.7(59)$ & $45.5 \pm 8.7(46)$ & $51.0 \pm 15.6(51)$ \\
White & $2(29)$ & $4(57)$ & $1(14)$ \\
Hispanic/Latino & $3(43)$ & $4(57)$ & 0 \\
\hline
\end{tabular}




\section{Continued}

\begin{tabular}{cccc}
\hline Black & \\
Native American Indian & $1(50)$ & 0 & 0 \\
LOS (days) & 0 & 0 & $1(100)$ \\
Male/female & $56.5 \pm 19.7(55)$ & $29.6 \pm 10.8(34)$ & $77.0 \pm 1.4(77)$ \\
Number of admissions & $1.8 \pm 1.0(1.5)$ & $2 \pm 1(2)$ & $2 / 0$ \\
\%TBSA & $3.7 \pm 2.6(3)$ & $1.0 \pm 0.3(1)$ & $1 \pm 0(1)$ \\
BMI (kg/m ${ }^{2}{ }^{+} p=0.003$ & $23.3 \pm 2.9(23)$ & $+32.5 \pm 4.5(32)$ & $26.4 \pm 0.8(26)$ \\
Burn injury ${ }^{\dagger \dagger}$ & $5(33)$ & $6(40)$ & $2(13)$ \\
NSTI & $1(33)$ & $2(67)$ & 0 \\
Admission gangrene & $1(25)$ & $3(75)$ & 0 \\
Diabetes $p=0.038$ & $2(18)$ & $7(64)$ & $2(18)$ \\
Cardiac & $3(43)$ & $3(43)$ & $1(14)$ \\
Hypertension & $3(38)$ & $5(62)$ & 0 \\
DVT & $1(25)$ & $3(75)$ & 0 \\
PVD & $1(100)$ & 0 & 0 \\
Renal & $2(40)$ & $2(40)$ & $1(20)$ \\
Alcohol + Drugs & $4(50)$ & $1(13)$ & 0 \\
Discharge home & $1(13)$ & $7(88)$ & 0 \\
Discharge SNF & $5(62)$ & $1(13)$ & $0.725)$ \\
Homeless & $2(33)$ & $076)$ & 0 \\
\hline
\end{tabular}

Mean \pm standard deviation (median); Number (percent) $=\#(\%)$; dHACM $=$ dehydrated human amnion-chorion membrane; $\mathrm{dHCM}$ = decellularized human collagen matrix; total body surface area (TBSA); length of stay = LOS; BMI = body mass index; NSTI = necrotizing soft tissue infections (these three cases had necrotizing fasciitis); ${ }^{\dagger \dagger}$ two (13\%) additional burn injuries (hand and forearm); DVT = deep vein thrombosis; PVD = peripheral vein disease; SNF = skilled nursing facility; two male patients had $1 \%$ TBSA hand-forearm full thickness burn injuries in addition to their leg-foot involvement; their combined age was $29.5 \pm 14.8$ (30) years. ${ }^{\dagger}$ The Black patient, who died with a total 95\% TBSA, also had a hand/forearm burn.

Table 2. dHACM and dHCM treatment timeline.

\begin{tabular}{|c|c|c|c|c|c|}
\hline & Leg & Foot & Leg \& Foot & Hand/Forearm & Combined \\
\hline Total surgeries & $8.3 \pm 1.8(9)$ & $7.4 \pm 1.6(8)$ & $13.0 \pm 2.8(11)$ & $2 \pm 0(2)$ & $7.8 \pm 3.0(8)$ \\
\hline Tissue debrided $\left(\mathrm{cm}^{2}\right)$ & $388.3 \pm 262.6(425)$ & $153.8 \pm 100.9(140)$ & $600.0 \pm 424.3(600)$ & $133.0 \pm 95.5(133)$ & $279.2 \pm 248.7(188)$ \\
\hline Injury to admit (days) & $13.7 \pm 22.7(4)$ & $12.1 \pm 14.3(8)$ & $2.5 \pm 2.1(3)$ & -- & $10.2 \pm 16.2(3)$ \\
\hline Days to TX & $43.5 \pm 38.4(34)$ & $16.3 \pm 8.3(14)$ & $19.0 \pm 4.2(19)$ & -- & $26.2 \pm 25.8(16)$ \\
\hline TX to discharge (days) & $26.7 \pm 15.0(25)$ & $20.0 \pm 12.2(20)$ & $58.0 \pm 5.7(58)$ & -- & $29.3 \pm 18.8(26)$ \\
\hline TX to STSG (days) & $20.2 \pm 16.9(14)$ & $28.7 \pm 17.6(23)$ & $37.5 \pm 6.4(38)$ & -- & $27.3 \pm 15.4(25)$ \\
\hline NPWT (days) & $17.8 \pm 9.5(18)$ & $16.9 \pm 8.0(15)$ & $36.5 \pm 7.8(37)$ & $14.0 \pm 0(14)$ & $19.9 \pm 10.5(14)$ \\
\hline Autograft $\left(\mathrm{cm}^{2}\right)$ & $399.0 \pm 250.8(350)$ & $90.0 \pm 61.2(83)$ & $1025 \pm 601.0$ & $150.0 \pm 70.0(150)$ & $325.7 \pm 381.4(200)$ \\
\hline
\end{tabular}

Mean \pm standard deviation (median); $\mathrm{dHACM}=$ dehydrated human amnion-chorion membrane; dHCM = decellularized human collagen matrix; TX = treatment with dHACM/dHCM; STSG = split thickness skin graft; OR TED = operating room tangential excision debridement; Leg \& Feet versus Feet in OR TED $p=0.029$; Leg \& Foot versus the Leg and the Foot: days TX to discharge $p=0.0189$. 
Table 3. dHACM and dHCM cost summary.

\begin{tabular}{cccccc}
\hline & Leg & Foot & Leg-Foot & Upper Extremity & Combined \\
\hline dHACM $^{*}$ & $5866 \pm 4634$ & $13,204 \pm 7847$ & $127,3778 \pm 50,491$ & $6840 \pm 0$ & $23,298 \pm 41,660$ \\
cost \$USD & $(4518)$ & $(13,240)$ & $(127,378)$ & $(6840)$ & $(8090)$ \\
dHCM ${ }^{*}$ & $5167 \pm 4810$ & $6675 \pm 2844$ & $27,700 \pm 4384$ & $4100 \pm 0$ & $8222 \pm 7894$ \\
cost USD & $(3100)$ & $(6200)$ & $(27,700)$ & $(4100)$ & $(5150)$ \\
dHACM/dHCM & $11,033 \pm 7963$ & $18,479 \pm 8146$ & $142,778 \pm 34,510$ & $10,940 \pm 0$ & $28,970 \pm 42,935$ \\
Total cost \$USD & $(8668)$ & $(18,610)$ & $(142,778)$ & $(10,940)$ & $(15,410)$ \\
\hline
\end{tabular}

Mean \pm standard deviation (median); $\$ \mathrm{USD}=\$$ United States dollar; ${ }^{\star} \mathrm{dHACM}=$ dehydrated human amnion/chorion membrane, (MiMedx Group Inc., Marietta, GA); ${ }^{* *} \mathrm{dHCM}=$ decellularized human collagen matrix, (MiMedx Group Inc., Marietta, GA).

\subsection{Outcomes}

Nine (53\%) patients completed treatment in one admission, three (18\%) were readmitted once, and five (29\%) were readmitted twice for either autograft placement or infection. After treatment with $\mathrm{dHACM} / \mathrm{dHCM}$, thirteen patients received autografts, two underwent a delayed primary closure, and one had autografts and flaps to cover bilateral knee defects. Four (22\%) of the patients had or required toe or partial foot amputations on admission due to gangrene or late presentation. Of two patients who failed the $\mathrm{dHACM} / \mathrm{dHCM}$ treatment, one required a below knee amputation, and another had an infected foot wound on readmission that required a trans-metatarsal amputation. These two patients did not respond to treatment due to one or more of the following factors: poorly controlled diabetes, infection, and inadequate generation of granulation tissue. Eight $(47 \%)$ patients underwent bone trephination in the wound area to stimulate granulation tissue development. Ten (59\%) patients either presented with or developed an infection (cellulitis, septic shock) during the hospitalization. Seven patients had unsuccessful trials with a bilaminate sheet composed of cross-linked bovine tendon collagen and shark glycosaminoglycans (chondroitin-6-sulfate) with a silicone sheet cover, Integra ${ }^{\circledR}$, (Integra Life Sciences, Princeton, NJ) prior to treatment with the placental-derived allograft dressings. One patient had a successful incorporation of the Integra ${ }^{\circledR}$ into the wound after dHACM/dHCM supported formation of adequate granulation tissue in the wound bed. Significantly more patients with foot salvage were discharged home compared to those with leg or leg and foot salvage, who were discharged to skilled nursing facilities, $p=0.005$. There was one (5.9\%) of seventeen patients who succumbed to a $95 \%$ TBSA flame burn after a 323-day hospitalization. Duration follow-up for thirteen of the seventeen patients was a median (IQR) of 438 (116 - 489) days with retained limbs and no complications. The four patients had no follow-up: two required amputations, one was lost to follow-up, and one died from the severe burn injury. Patients were seen "as needed" in clinic for one and a half years until the study ended in November 2020.

\subsection{Case 1}

A 79-year-old male was admitted to the burn center three days after sustaining a full thickness $2 \%$ total body surface area (TBSA) contact burn to his right lower 
extremity (RLE) after falling on a space heater at home. His co-morbidities consisted of Type 2 diabetes $(\mathrm{HbAlc}=7.2 \%)$, hypertension, dyslipidemia, dementia, and a history of a coronary artery bypass (CABG) surgery. His medications included aspirin and an antiplatelet medication. Evaluation of the injured extremity revealed peripheral vascular disease. During a bilateral lower extremity angiogram, a right popliteal artery atherectomy and balloon angioplasty were performed to improve blood flow. He had nine OR visits for tangential excisional debridement $\left(400 \mathrm{~cm}^{2}\right)$ during an 89-day hospital stay. After two unsuccessful trials with Integra ${ }^{\circledR}$, his treatment with $\mathrm{dHACM} / \mathrm{dHCM}$ started on day 42 of hospitalization. Sixteen days after the initial application of $\mathrm{dHACM} / \mathrm{dHCM}$, his wound was autografted (Figures 6-8). In total, the patient received $350 \mathrm{~cm}^{2}$ of dHACM and $2000 \mathrm{mg}$ of $\mathrm{dHCM}$ at a combined product only cost of $\$ 17,780$. He has not reported any issues or complications in follow-up for the past two years.

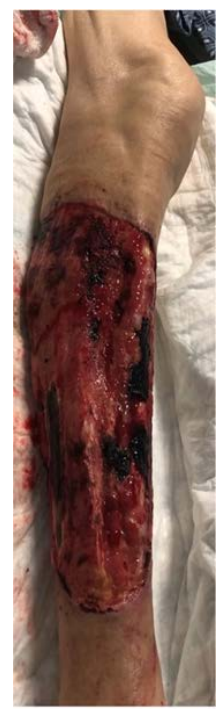

Figure 6. Right leg contact burn with exposed bone on admission.

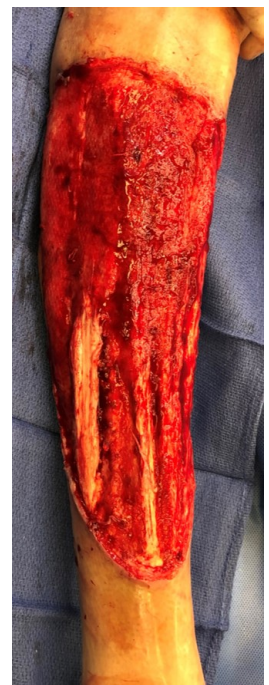

Figure 7. Exposed bone and tendon after debridement. 


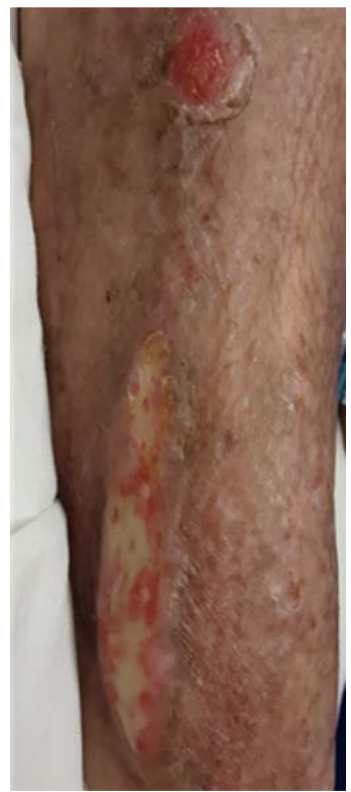

Figure 8. Day 122 after initial injury.

\subsection{Case 2}

A thirty-one-year-old male arrived in the emergency room with left lower (LLE) extremity pain, swelling, and fever. He was admitted to the medical intensive care unit for septic shock, NSTI, bacteremia, acute renal failure, and deep vein thrombosis of the affected leg. After transfer to the burn center, he underwent left leg fasciotomies for compartment syndrome, and six debridement procedures of the foot plantar surface to remove necrotic tissue and prepare the wound bed for closure (Figure 9, Figure 10). With intravenous antibiotics, appropriate renal treatment, and anticoagulation, the patient stabilized. During his 22-day hospitalization, his lateral and medial leg fasciotomies were closed using the DermaClose device (Synovis, Birmingham, AL), which is a continuous external

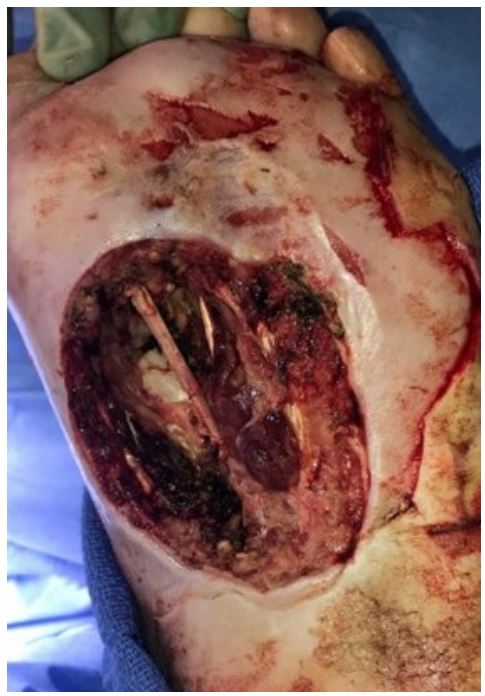

Figure 9. Debrided plantar wound on admission. 


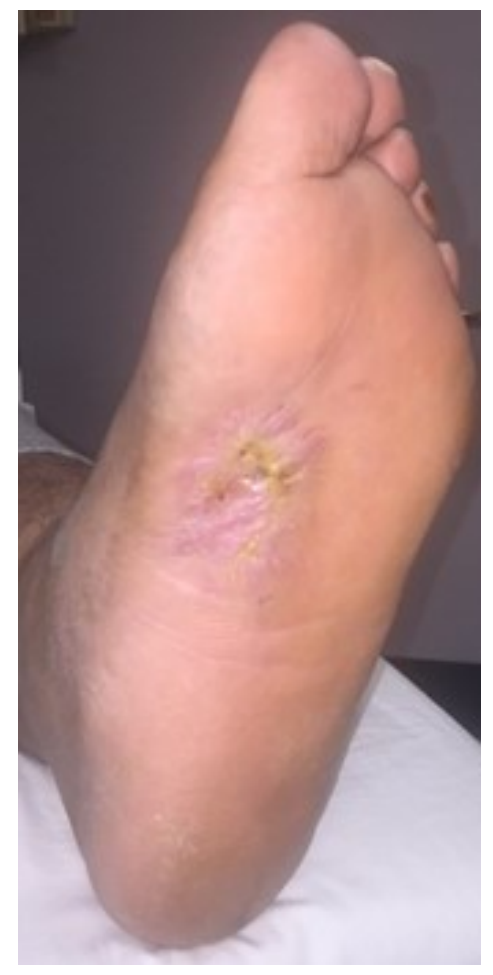

Figure 10. Healed scar during clinic visit.

tissue expander. The left foot plantar wound received dHACM/dHCM with bolstering NPWT set at $100 \mathrm{mmHg}$ continuously, on the $13^{\text {th }}$ day of his hospital stay. He had an additional one-day hospitalization for autografting of the plantar wound $\left(50 \mathrm{~cm}^{2}\right)$. In total, he received $720 \mathrm{~cm}^{2}$ of $\mathrm{dHACM}$ and $4000 \mathrm{mg}$ of dHCM at a combined product only cost of $\$ 35,560$. His follow-up at 328 days since injury has shown complete closure and no complications.

\subsection{Case 3}

A forty-year-old male was intubated on admission to the burn center after he was "found down" outside on the pavement during the summer months in South-Central Arizona. He was treated for fulminant diabetic ketoacidosis (admission glucose level $1053 \mathrm{mg} / \mathrm{dl}$; HbAlc was 7.9\%. He had 14\% TBSA full thickness contact burns of his scalp, right upper extremity, and bilateral lower extremities. The burns on his legs, knees, and feet had exposed tendon and bone. His hospitalization was complicated by a myocardial infarction, electrolyte imbalances, and diabetic management. During his 78-day hospitalization, he underwent thirteen OR visits for multiple debridements $\left(900 \mathrm{~cm}^{2}\right)$. A trial with Integra ${ }^{\circledR}$ was not successful. Treatment with $\mathrm{dHACM} / \mathrm{dHCM}$ was started along with NPWT on the $16^{\text {th }}$ day after injury. Thirty-three-days later the wound bed was sufficiently prepared to receive a $1450 \mathrm{~cm}^{2}$ autograft (Figures 11-14). In total, he received $4479 \mathrm{~cm}^{2}$ of dHACM and 13,000 $\mathrm{mg}$ of dHCM at a combined product only cost of $\$ 167,180$. He achieved complete closure of all his wounds with no complications is currently walking with a cane. 


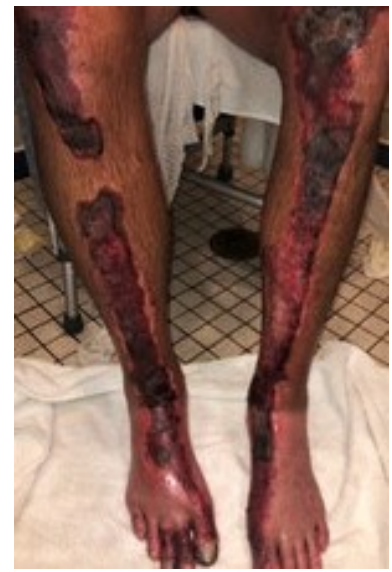

Figure 11. Debrided pavement contact burns (hospital day four).

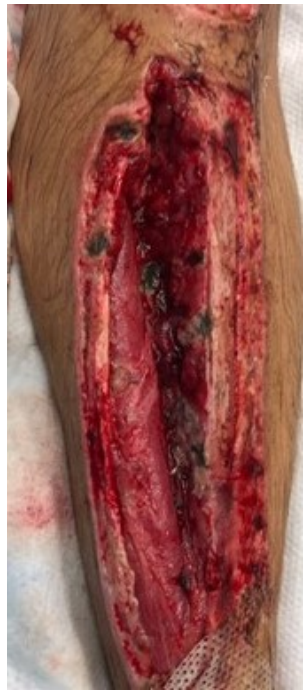

Figure 12. After debridement, thrombosed vessels with exposed bone/tendon.

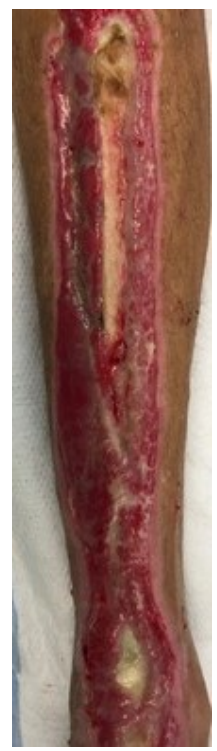

Figure 13. Granulation tissue formation starting to cover wound defect. 


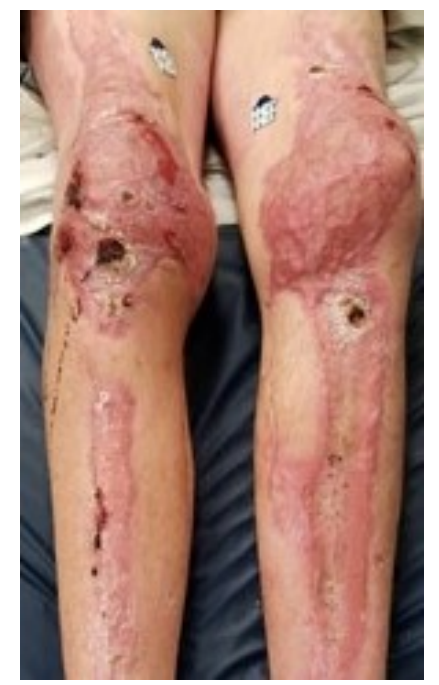

Figure 14. Treated with $\mathrm{dHACM} / \mathrm{dHCM}$ and bilatral knee flaps.

\section{Discussion}

In this study, patients who received $\mathrm{AHACM}$ in tandem with $\mathrm{AHCM}$ as a barrier and placental-based connective tissue matrix, respectively, over exposed deep tissue structures demonstrated limb preservation in 24 of 26 (92\%) extremities (eleven legs, twelve feet, and two hand and forearms). As expected, patients with both foot and leg involvement underwent more surgeries, received more $\mathrm{dHACM} / \mathrm{dHCM}$, required longer NPWT treatment duration, and had a longer LOS than single foot or leg injury patients. Although all patients included in this analysis were candidates for amputation, a limb preservation rate of $92 \%$ observed in this complex wound cohort should give providers pause to reevaluate current amputation protocols, and consider alternative pathways weighted towards limb salvage. Table 4 lists the current literature where placental tissue was successfully used to cover exposed bone and tendon, and to support granulation tissue growth that is crucial to achieve limb salvage in this targeted study population.

While bone trephination promoted granulation tissue generation, adequate coverage of tendons was still an occasional problem. One solution might be to consider the injection of human placental-derived tissue into the culprit tendon as reported by Lei et al. [11]. When this approach was used, the treating provider observed a reduction in fibrous tissue formation in the injured tendons and ligaments as well as decreased inflammation, which may have been factors in the inhibition of granulation tissue adherence to the tendon surface [11].

In 2006, Parrett et al. reported that with autografts and flaps, seven of 40 (17.5\%) limbs required amputations [1]. In this limb salvage study, there were two (8\%) amputations after treatment with $\mathrm{dHACM} / \mathrm{dHCM}$ due to one or more of the following factors: poorly controlled diabetes, infection, and inadequate granulation tissue generation. For wounds with exposed bone and tendons in patients with burns, trauma and infections, skin grafts and flaps have been the main deterrents to amputation. While many of these patients may not have been 
Table 4. Literature reports on the use of placental membranes for exposed tendon/bone wounds.

\begin{tabular}{|c|c|c|c|c|}
\hline Author & Year & Cases & Wound & Placental allografts \\
\hline Sabella [5] & 1913 & 5 & 4 burn, 1 trauma & $\begin{array}{c}\text { amnion/chorion/umbilical cord, } \\
\text { normal saline }\end{array}$ \\
\hline Stern $[6]$ & 1913 & 12 & $\begin{array}{c}11 \text { burn }\left(\leq 9 \mathrm{~cm}^{2}\right) \\
1 \text { trauma }\end{array}$ & $\begin{array}{c}\text { amnion/chorion; normal saline; } \\
\text { petrolatum wax }\end{array}$ \\
\hline Gruss [14] & 1978 & 7 & trauma & $\begin{array}{c}\text { amnion/chorion; normal saline; } \\
0.025 \% \text { Na hypochlorite }\end{array}$ \\
\hline Sheikh [27] & 2013 & 4 & trauma & $\mathrm{dHACM}^{*}$ \\
\hline Torabi [28] & 2015 & 7 & trauma & amnion/chorion; STSG \\
\hline Frykberg [16] & 2016 & 30 & diabetic ulcers & $\begin{array}{l}\text { viable cryopreserved human } \\
\text { placental membrane (vCHPM) }\end{array}$ \\
\hline Schlanser [22] & 2018 & 1 & trauma & $\operatorname{mdHACM}^{* *}$ \\
\hline Current Study & 2020 & 17 & burn $+\mathrm{NF}$ & $\mathrm{dHACM}^{*}$ and $\mathrm{dHCM}^{*}$ \\
\hline
\end{tabular}

$\mathrm{NF}=$ necrotizing fasciitis; STSG $=$ split thickness skin graft; $*($ MiMedx Group Inc., Marietta, GA $)$; mdHACM ${ }^{* *}=$ micronized dHACM, (MiMedx, Marietta, GA).

ideally suited for flap reconstruction, they were candidates for dHACM and/or $\mathrm{dHCM}$. The use of flaps for covering these wounds is important but has distinctive problems and complications [29]-[34]. Some of the flap complications may be partial or complete failure in the transfer, as well as wound congestion, full or partial flap necrosis, wound dehiscence, donor site deformity or morbidity such as loss of physical function with the use of muscle flaps [29]-[34]. Of all sites, lower extremity flaps have the highest rate of failure [34]. Some of the prominent risk factors for flap microsurgery complications are co-morbidities such as diabetes, arteriopathy, and age $>60$-years [31]. Eleven (65\%) of the patients in this study had diabetes; ages varied from 19 - 79 years with five patients older than 60 -years, and one patient had peripheral vascular disease [31]. Treatment with placental allografts in this study did not have the same complication profile seen in flap reconstruction and did not lead to the extraordinary lifestyle changes that transpire following amputations. The consequences of decisions that lower limb amputations are the most practical and inexpensive, do not always take into consideration individual future quality of life (QOL), or life changes, possibilities, and expectations [35]. There is "no one size fits all;" amputees may have a low hospitalization cost for the amputation, but a lifetime of prosthetic limb and wheelchair issues and expenses.

Prostheses are not always the best alternative for amputations; they must be appropriately constructed for the patient to adjust to limited functional capacity. With rehabilitation and therapy, physical attributes may become acceptable but frequently the mental aspects of recovery may severely impede the amputee's quality of life [36]. While an amputation may curtail hospital and medical costs at the time of injury, future medical costs for patients and society have been reported between $\$ 10,000$ and $\$ 60,000$ per prosthesis [37] [38]. The Veterans Hospital Administration (VHA) has vast experience with amputations from the past 
Iraq and Afghanistan conflicts, which maimed our military personnel through improvised explosive devices (IED) [36] [37]. They have reported the medical costs to average \$1.4 million per amputee [37] [38]. Among veterans with diabetes, the individual mean cost associated with a lower extremity amputation in the VHA system in FY2010 was $\$ 60,647$ [38]. When inflated to 2020 levels via a consumer price index calculator (US Bureau of Labor Statistics), the adjusted mean cost would be $\$ 72,076$ [39]. In diabetic foot ulcer treatment, the total extra healthcare costs of a lower extremity amputation versus no amputation, including a two-year follow-up, was between $\$ 40,000$ and $\$ 60,000$ [40]. For persons with a unilateral lower extremity amputation, the two-year health care cost, including initial hospitalization, inpatient rehabilitation, outpatient physical therapy, and the purchase and maintenance of a prosthetic device, was estimated to be $\$ 91,106$ [41]. In a trauma study of 545 patients with a unilateral lower extremity injury, lifetime healthcare costs were higher for amputees $(\$ 509,275)$ than for those who had limb reconstruction $(\$ 163,282)[42]$.

Table 5, compares the advantages and disadvantages of these treatment modalities. Viewed from this perspective, the attempt to salvage the limb may be the

Table 5. Advantages and disadvantages of allograft placental membranes, flaps and prostheses.

\begin{tabular}{|c|c|c|}
\hline dHACM/dHCM & Flaps/tissue transfers & Prostheses \\
\hline \multicolumn{3}{|c|}{ Advantages } \\
\hline $\begin{array}{l}{ }^{\star} \text { Concurrent } \mathrm{NPWT} \text { aids tissue } \\
\text { regeneration and moisture } \\
\text { management }\end{array}$ & $\begin{array}{l}\text { No Immunologic products; } \\
\text { autologous tissue used }\end{array}$ & $\begin{array}{l}\text { Different types of } \\
\text { prostheses available }\end{array}$ \\
\hline Extremities retained & $\begin{array}{l}\text { Immediate wound coverage with } \\
\text { placement }\end{array}$ & $\begin{array}{l}\text { Artificial limb or } \\
\text { appendage }\end{array}$ \\
\hline $\begin{array}{l}\text { No other body parts used for } \\
\text { healing or reconstruction }\end{array}$ & Potentially shorter LOS & Potentially shorter LOS \\
\hline Improved & & Treatment occurs out of \\
\hline Quality of Life & & hospital \\
\hline \multirow[t]{2}{*}{$\begin{array}{l}\text { Treatment easily transferred to } \\
\text { outpatient setting }\end{array}$} & & Wheelchair alternative \\
\hline & Disadvantages & \\
\hline $\begin{array}{l}\text { Direct wound visualization is not } \\
\text { possible while NPWT drape is in } \\
\text { place. }\end{array}$ & $\begin{array}{l}\text { NPWT cannot be applied over flap } \\
\text { or tissue transfer; tissue regeneration } \\
\text { and healing have no NPWT benefits. }\end{array}$ & Expensive acquisition costs \\
\hline \multirow[t]{2}{*}{$\begin{array}{l}\text { If NPWT applied improperly over } \\
\text { healthy skin, it may lead to skin } \\
\text { trauma or breakdown }\end{array}$} & $\begin{array}{l}\text { Loss of a body part (muscle, skin) to } \\
\text { cover wound; functional disability } \\
\text { (walking; lifting oneself) due to lost } \\
\text { muscle or skin }\end{array}$ & $\begin{array}{l}\text { Increased lifelong expenses } \\
\text { and healthcare } \\
\text { maintenance }\end{array}$ \\
\hline & $\begin{array}{l}\text { Treatment cannot be transitioned to } \\
\text { the outpatient setting until healing } \\
\text { occurs }\end{array}$ & $\begin{array}{l}\text { Impaired } \\
\text { Quality of Life }\end{array}$ \\
\hline
\end{tabular}

${ }^{\star}$ NPWT $=$ negative pressure wound therapy. Advantages of NPWT are: 1) increases and expedites: granulation tissue generation; 2) increases vascularity; 3 ) removes pro-inflammatory biomarkers, produced by the body; 4). increases the flow of growth factors and nutrients to wounds. 
most affordable option in respect to both the preservation of quality of life and lower economic impact compared to a major amputation. Depending on payer financial incentives, allograft cost can be justified because of superior outcomes and patient-recognized values in the fee for service environments, or directly on cost in environments where reimbursement is outcome-based or capitated across an episode of care for an injury. Overall, the economic impact of an extremity amputation is notably higher than the short-term costs of the allograft material, even when combined with the nominal product application costs [43].

\section{Limitations}

This study shares similar limitations to other studies in that it is retrospective, dependent on the accuracy of medical records, lacks patient heterogeneity, and is subject to selection bias. Despite these limitations, it has shown that placental allografts for limb salvage, such as DHACM and DHCM, have increased the resources available to progress one more rung on the surgical reconstructive ladder, before subjecting a patient with expose bones and tendons to amputation.

\section{Conclusion}

In select limb salvage cases, $\mathrm{dHACM}$ and $\mathrm{dHCM}$ were observed as a promising alternatives to amputations, tissue transfer flaps or other techniques for secondary intention resolution of extremity wounds with bone and tendon exposure. Additional studies are needed to determine whether the use of these products results in improved patient outcomes compared to current wound care techniques, tissue flaps or amputations.

\section{Conflicts of Interest}

William Tettelbach, MD is currently the acting Principal Medical Officer for the MiMedx Group, Inc. There are no other conflicts of interest to declare.

\section{References}

[1] Parrett, B.M., Pomahac, B., Demling, R.H. and Orgill, D.P. (2006) Fourth Degree Burns to the Lower Extremity with Exposed Tendon and Bone: A Ten-Year Experience. Journal of Burn Care \& Research, 27, 34-39. https://doi.org/10.1097/01.bcr.0000192265.20514.c5

[2] Sahin, I., Eski, M., Acikel, C., Kapaj, R., Alhan, D. and Isik, S. (2012) The Role of Negative Pressure Wound Therapy in the Treatment of Fourth-Degree Burns. Trends and New Horizons. Annals of Burns and Fire Disasters, 25, 92-97.

[3] Simman, R. (2009) Wound Closure and the Reconstructive Ladder in Plastic Surgery. The Journal of the American College of Certified Wound Specialists, 1, 6-11. https://doi.org/10.1016/j.jcws.2008.10.003

[4] Glat, P.M. and Davenport, T. (2017) Using Dehydrated Human Amnion/Chorion Membrane Allografts as an Adjunctive Treatment along the Reconstructive Ladder. Annals of Plastic Surgery, 78, S14-S18. https://doi.org/10.1097/SAP.0000000000000980

[5] Sabella, N. (1913) Use of the Fetal Membranes in Skin Grafting. Medication Recon- 
ciliation, 83, 478-480.

[6] Stern, M. (1913) The Grafting of Preserved Amniotic Membrane to Burned and U1cerated Surfaces, Substituting Skin Grafts. JAMA, 60, 973-974.

https://doi.org/10.1001/jama.1913.04340130021008

[7] Glat, P.M. (2017) The Evolution of Burn Injury Management: Using Dehydrated Human Amnion/Chorion Membrane Allografts in Clinical Practice. Annals of Plastic Surgery, 78, S1. https://doi.org/10.1097/SAP.0000000000000982

[8] Koob, T.J., Rennert, R., Zabek, N., Massee, M., Lim, J.J., Temenoff, J.S., et al. (2013) Biological Properties of Dehydrated Human Amnion/Chorion Composite Graft: Implications for Chronic Wound Healing. International Wound Journal, 10, 493 500. https://doi.org/10.1111/iwj.12140

[9] Koob, T.J., Lim, J.J., Zabek, N. and Massee, M. (2015) Cytokines in Single Layer Amnion Allografts Compared to Multilayered Amnion/Chorion Allografts for Wound Healing. Journal of Biomedical Materials Research Part B: Applied Biomaterials, 103, 1133-1140. https://doi.org/10.1002/jbm.b.33265

[10] Lei, J., Priddy, L.B., Lim, J.J., Massee, M. and Koob, T.J. (2017) Identification of Extracellular Matrix Components and Biological Factors in Micronized Dehydrated Human Amnion/Chorion Membrane. Advances in Wound Care, 6, 43-53. https://doi.org/10.1089/wound.2016.0699

[11] Lei, J., Priddy, L.B., Lim, J.J. and Koob, T.J. (2017) Dehydrated Human Amnion/chorion Membrane (dHACM) Allografts as a Therapy for Orthopedic Tissue Repair. Techniques in Orthopaedics, 32, 147-157. https://doi.org/10.1097/BTO.0000000000000229

[12] Reilly, D.A., Hickey, S., Glat, P., Lineaweaver, W.C. and Goverman, J. (2017) Using Dehydrated Human Amnion/Chorion Membrane Allografts for Acute and Reconstructive Burn Care. Annals of Plastic Surgery, 78, S19-S26. https://doi.org/10.1097/SAP.0000000000000981

[13] Ahuja, N., Jin, R., Powers, C., Billi, A. and Bass, K. (2020) Dehydrated Human Amnion/Chorion Membrane as a Treatment for Pediatric Burns. Advances in Wound Care, 9, 602-611. https://doi.org/10.1089/wound.2019.0983

[14] Gruss, J.S. and Jirsch, D.W. (1978) Human Amniotic Membrane: a Versatile Wound Dressing. Canadian Medical Association Journal, 118, 1237-1246.

[15] Cazzell, S., Stewart, J., Agnew, P.S., et al. (2018) Randomized Controlled Trial of Micronized Dehydrated Human Amnion/Chorion Membrane (dHACM) Injection Compared to Placebo for the Treatment of Plantar Fasciitis. Foot \& Ankle International, 39, 1151-1161. https://doi.org/10.1177/1071100718788549

[16] Frykberg, R.G., Gibbons, G.W., Walters, J.L., Wukich, D.K. and Milstein, F.C. (2017) A Prospective, Multicentre, Open-Label, Single-Arm Clinical Trial for Treatment of Chronic Complex Diabetic Foot Wounds with Exposed Tendon and/or Bone: Positive Clinical Outcomes of Viable Cryopreserved Human Placental Membrane. International Wound Journal, 14, 569-577.

https://doi.org/10.1111/iwj.12649

[17] Tettelbach, W., Cazzell, S., Reyzelman, A.M., Sigal, F., Caporusso, J.M. and Agnew, P.S. (2019) A Confirmatory Study on the Efficacy of Dehydrated Human Amnion/Chorion Membrane dHACM Allograft in the Management of Diabetic Foot Ulcers: a Prospective, Multicentre, Randomised, Controlled Study of 110 Patients from 14 Wound Clinics. International Wound Journal, 16, 19-29. https://doi.org/10.1111/iwj.12976

[18] Koob, T.J., Lim, J.J., Massee, M., Zabek, N. and Denoziére, G. (2014) Properties of 
Dehydrated Human Amnion/Chorion Composite Grafts: Implications for Wound Repair and Soft Tissue Regeneration. Journal of Biomedical Materials Research Part B: Applied Biomaterials, 102, 1353-1362. https://doi.org/10.1002/jbm.b.33141

[19] Koob, T.J., Lim, J.J., Massee, M, Zabek, N., Rennert, R., Gurtner, G., et al. (2014) Angiogenic Properties of Dehydrated Human Amnion/Chorion Allografts: Therapeutic Potential for Soft Tissue Repair and Regeneration. Vascular Cell, 6, 10.

[20] Legemate, C.M., Goei, H., Gostelie, O.F.E., Nijhuis, T.H.J., van Baar, M.E., van der Vlies, C.H. and Dutch Burn Repository Group. (2019) Application of Hydrosurgery for Burn Wound Debridement: An 8-Year Cohort Analysis. Burns, 45, 88-96. https://doi.org/10.1016/j.burns.2018.08.015

[21] Chen, W.F., Poulakidas, S.J., Kowal-Vern, A. and Villare, R.C. (2010) Trephination and Subatmospheric Pressure Therapy in the Management of Extremity Exposed Bone. The Journal of Trauma: Injury, Infection, and Critical Care, 69, 1591-1596. https://doi.org/10.1097/TA.0b013e3181edba5e

[22] Schlanser, V., Dennis, A., Ivkovic, K., Joseph, K., Kaminsky, M., Messer, T., et al. (2018) Placenta to the Rescue: Limb Salvage Using Dehydrated Human Amnion/ Chorion Membrane. Journal of Burn Care \& Research, 39, 1048-1052.

[23] Argenta, L.C. and Morykwas, M.J. (1997) Vacuum-assisted Closure: a New Method for Wound Control and Treatment: Clinical Experience. Annals of Plastic Surgery, 38, 563-577. https://doi.org/10.1097/00000637-199706000-00002

[24] Chang, K.P., Tsai, C.C., Lin, T.M., Lai, C.S. and Lin, S.D. (2001) An Alternative Dressing for Skin Graft Immobilization: Negative Pressure Dressing. Burns, 27, 839842. https://doi.org/10.1016/S0305-4179(01)00052-3

[25] Moisidis, E., Heath, T., Boorer, C., Ho, K. and Deva, A.K. (2004) A Prospective Blinded Randomized Controlled Clinical Trial of Topical Negative Pressure Dressing in Skin Grafting. Plastic and Reconstructive Surgery, 114, 917-922. https://doi.org/10.1097/01.PRS.0000133168.57199.E1

[26] Scherer, L.A., Shiver, S., Chang, M., Meredith, J.W. and Owings, J.T. (2002) The Vacuum Assisted Closure Device: A Method of Securing Skin Grafts and Improving Graft Survival. Archives of Surgery, 137, 930-934.

https://doi.org/10.1001/archsurg.137.8.930

[27] Sheikh, E.S., Sheikh, E.S. and Fetterolf, D.E. (2014) Use of Human Amniotic Membrane Allografts to Promote Healing in Patients with Refractory Non-healing Wounds. International Wound Journal, 11, 711-717. https://doi.org/10.1111/iwj.12035

[28] Torabi, R., Strong, A.L., Hogan, M.E., Dupin, C.L., Tessler, O. and Lau, F.H. (2016) Bone and Tendon Coverage via Dehydrated Human Amniotic/chorionic Membrane and Split-thickness Skin Grafting. Journal of Reconstructive Microsurgery Open, 1 , 59-62. https://doi.org/10.1055/s-0036-1571279

[29] Koul, A.R., Patil, R.K. and Nahar, S. (2013) Unfavourable Results in Free Tissue Transfer. Indian Journal of Plastic Surgery, 46, 247-255.

https://doi.org/10.4103/0970-0358.118600

[30] Bekara, F., Herlin, C., Mojallal, A., Sinna, R., Ayestaray, B., Letois, F., Pierre Chavoin, J., Garrido, I., Grolleau, J.L. and Chaput, B. (2016) A Systemic Review and Meta-analysis of Perforator-Pedicle Propeller Flaps in Lower Extremity Defects: Identification of Risk Factors for Complications. Plastic and Reconstructive Surgery, 137, 314-331. https://doi.org/10.1097/PRS.0000000000001891

[31] Qian, Y., Li, G., Zang, H., Cao, S., Liu, Y., Yang, K. and Mu, L. (2018) A systemic review and meta-analysis of free-style flaps: risk analysis of complications. Plastic 
and Reconstructive Surgery-Global Open, 6, e1651. https://doi.org/10.1097/GOX.0000000000001651

[32] Rodriguez-Collazo, E., Khan, A., DiPierro, D. and Khan, I. (2018) A Systemic Review of Outcomes and Flap Selection Following Lower Extremity Free Tissue Transfer versus Vascularized Perforator Pedicle Flap Transfer in Lower Limb Reconstruction. International Journal of Orthoplastic Surgery, 1, 55-66.

[33] Khan, M.M., Cheruvu, V.P.R., Krishna, D., Laitonjam, M., Minz, R. and Joshi, R. (2020) Post-traumatic Wounds over the Dorsum of the Foot-Our Experience. International Journal of Burns and Trauma, 10, 137-145.

[34] Stranix, J.T., Lee, Z.H., Jacoby, A., Anzai, L., Mirrer, J., Avraham, T., Thanik, V., Levine, J.P. and Saadeh, P.B. (2018) Forty Years of Lower Extremity Take-backs: Flap Type Influences Salvage Outcomes. Plastic and Reconstructive Surgery, 141, 1282-1287. https://doi.org/10.1097/PRS.0000000000004322

[35] Sinha, R., van den Heuvel, W.J.A. and Arokiasamy, P. (2011) Factors Affecting Quality of Life in Lower Limb Amputees. Prosthetics and Orthotics International, 35, 90-96. https://doi.org/10.1177/0309364610397087

[36] Al-Thani, H., Sathian, B. and El-Menyar, A. (2019) Assessment of Healthcare Costs of Amputation and Prosthesis for Upper and Lower Extremities in a Qatari Healthcare Institution: A Retrospective Cohort Study. BMJ Open, 9, e024963. https://doi.org/10.1136/bmjopen-2018-024963

[37] Blough, D.K., Hubbard, S., McFarland, L.V., Smith, D.G., Gambel, J.M. and Reiber, G.E. (2010) Prosthetic Cost Projections for Service Members with Major Limb Loss from Vietnam and OIF/OEF. Journal of Rehabilitation Research and Development, 47, 387-402.

[38] Franklin, H., Rajan, M., Tseng, C-L., Pogach, L., Sinha, A., Mph, M. (2014) Cost of Lower-Limb Amputation in US Veterans with Diabetes Using Health Service Data in the Fiscal Years 2004 and 2010. Journal of Rehabilitation Research \& Development, 51, 1325-1330.

[39] United States Bureau of Labor Statistics Data Tools: CPI Inflation Calculator. https://www.bls.gov/data/inflation calculator.htm

[40] Carls, G.S., Gibson, T.B., Driver, V.R., Wrobel, J.S., Garoufalis, M.G., Defrancis, R.R., Wang, S., Bagalman, J.E. and Christina, J.R. (2011) The Economic Value of Specialized Lower-Extremity Medical Care by Podiatric Physicians in the Treatment of Diabetic Foot Ulcers. Journal of the American Podiatric Medical Association, 101, 93-115.

[41] Amputee Coalition (2014) Arizona Fact Sheet. https://www.amputee-coalition.org/resources/arizona-2/

[42] MacKenzie, E.J., Jones, A.S., Bosse, M.J., Castillo, R.C., Pollak, A.N., Webb, L.X., Swiontkowski, M.F., Kellam, J.F., Smith, D.G., Sanders, R.W., Jones, A.L., Starr, A.J., McAndrew, M.P., Patterson, B.M. and Burgess, A.R. (2007) Health-Care Costs Associated with Amputation or Reconstruction of a Limb-Threatening Injury. The Journal of Bone \& Joint Surgery, 89, 1685-1692. https://doi.org/10.2106/00004623-200708000-00003

[43] Fetterlof, D.E. (2019) Estimating the Economic Value of Emerging Technologies in Chronic Wound Therapy. International Wound Journal, 16, 1391-1397.

https://doi.org/10.1111/iwj.13202 